\title{
An evaluation of the knowledge of patiens of the need to follow suitable lifestyles after hart surgery
}

\begin{abstract}
Introduction. Cardiovascular diseases are the leading cause of premature death in Europe. In Poland, the percentage mortality is 2,5 times higher than in Western European countries.

Aim. To assess patients' knowledge of the need for diet and physical activity after cardiac surgery.

Material and methods. The study involved a group of 150 patients after cardiac surgery. The research was conducted at the Department of Cardiac and Vascular Surgery, University Clinical Centre in Gdansk. The study used a questionnaire of our own design.

Results. Over half of the respondents stated that they had an average amount of knowledge with regard to healthy eating, while one in four had a less than average level of knowledge, and $16 \%$ opined that they had a superior knowledge of the same. These results are dependent on age and degree of formal education, and to adherence to dietary recommendations of gender, to financial situation and marital status. With regard to average dietary adherence, more women than men properly identified products harmful to human health. These last results bore little correlation to place of residence or degree of formal education. In addition, slightly more than half of the respondents (55.3\%) practiced some sort of physical activity, but up $44.7 \%$ does not do any. More active were women and younger people (of both sexes), and those with higher degrees of formal education.

Conclusions. Knowledge of patients with regard to diet after cardiac surgery is dependent on age and degree of formal education, and to adherence to dietary recommendations of gender, to financial situation and marital status. However, formal education and place of residence does not have a significant impact on the level of knowledge of products that are harmful to human health and behavior. Both sex, place of residence and degree of formal education have an impact on level of physical activity in general, as well as on its individual manifestations. More active are women, younger people and those with higher formal education.
\end{abstract}

Keywords: knowledge of patients, diet, motor activity.

DOI: $10.1515 /$ pjph-2015-0005

\section{INTRODUCTION}

Cardiovascular diseases are the leading cause of deaths in Poland, and in 2003, this figure constituted as much as $47 \%$ of all deaths in the country [1]. World-wide, the number of deaths attributed to cardiovascular diseases has decreased, e.g. in Finland by $20 \%$, and in the USA and Japan, by about $25-30 \%$ [1]. Preventive action, included that offered to persons threatened with atherosclerosis and related complications, has brought about this decline [2]. This activity is considered as being 'primary prevention'. What is deemed as 'secondary preventative action' is addressed to those who have had cardiovascular diseases [2]. This had bought a further decline in mortality even by as much as $27 \%$ more [2].

\section{AIM}

Our study is an evaluation of the knowledge of patients with respect to healthy eating and the need for physical activity after heart surgeries.

\section{MATERIAL AND METHODS}

Examinations were conducted in the Clinic of Cardiac Surgery and Vascular Surgery of the University Clinical Centre in Gdańsk. In total, 150 patients took part in the examination after their cardiac surgery. In gaining the necessary information, a diagnostic survey was used. This included a questionnaire that was then analyzed statistically. This questionnaire consisted of three parts and includes 22 questions. The first part contains 9 clinical and background questions, the second part of the question was an evaluation of knowledge of healthy eating practices, and the third part consisted

\footnotetext{
${ }^{1}$ Clinic of Cardiac Surgery and Vascular Surgery of the University Clinical Centre in Gdańsk, Poland

${ }^{2}$ Plant of the Nursing of the General Gdańsk Medical University, Poland
} 
of questions about physical activity and its influence on the human body. A statistical analysis was performed using the STATISTICA program (StatSoft, Krakow, Poland), utilizing Chi Square analysis and then the Spearmans test for the coefficient of correlation. Significance is considered if $p<0.05$.

\section{RESULTS}

In our study, 150 respondents took part in the examination. These were patients after cardiac surgery treatments. Over half (53.3\%) were male. Moreover, of the study, $14.7 \%$ were 80 years of age or older, while $22 \%$ were between 70 to 79 years of age. Most participants $(35.3 \%)$ were aged 60 up to 69 years, while $28 \%$ were between 40 to 59 years of age.

Just over half examined (54\%) were urban dwellers. About $33.3 \%$ had at least a vocational secondary education. Groups of people with only a primary education $(21.3 \%)$ or more advanced education than vocational (14.7\%) are less numerous. Over half of the respondents $(56 \%)$ were married, while $35.3 \%$ of the whole consisted of widows and widowers. Unmarried individuals are less numerous (4.7\%), and those divorced made up $4 \%$ of the total.

A straight majority $(82.7 \%)$ declared that they were the sole financial support within their family. About $10.7 \%$ considered their financial situation as being very good, while over half $(52.7 \%)$ assessed their financial as good, and $34.7 \%$ considered it as bad. Over the half of the respondents declared a rough average level of knowledge with respect to healthy eating, and $16 \%$ declared a superior knowledge of the same. What is more, $7.3 \%$ assessed their knowledge as very high, while $24.7 \%$ declared an inferior knowledge. Generally, younger persons have a greater knowledge of healthy eating than do more elderly people. The Spearman's coefficient of correlation of age and healthy eating knowledge is significant and negative. Moreover, a distinctive tendency is a positive correlation between degree of formal education attained and knowledge of healthy eating practices. Here, the Spearman's correlation is significant and positive $(\mathrm{p}=0.000)$ (Table 1).

With regard to knowledge of healthy eating practices, the majority had a knowledge about the need to eat regularly (average 2.17), however, less were aware of the need to limit salt consumption (average 1.93). With respect to the former, about $11.3 \%$ of all respondents were not aware of how much they were eating within one day's time (hence, displaying irregular trophism). In addition, almost half of the respondents $(47.4 \%)$ stated that they ate 3 or 4 meals per day, while $22 \%$ fully complied with the recommendation to eat more than 4 small meals per day, and $19.3 \%$ only ate twice to three times a day. Of the meals scheduled, only about a third of those surveyed ate their last meal 2 hours before sleeping, while $17.3 \%$ ate $3-4$ hours before bedtime. Moreover, only 9.3\% were taking milk or kefir or yoghurt several times per day. In addition, over half the participants in this study $(56.8 \%)$ know that the necessary dietary fibre can be found in fruits and vegetables, while $26.4 \%$ admitted to a lack of knowledge of this. Of note, more women than men followed dietetic recommendations $(21.73 \%$ versus $20.10 \%)$.

Of unhealthy life-style choices, $90.7 \%$ of those surveyed smoked, while $84 \%$ drank alcohol. Almost half of respondents $(44.7 \%)$ also enjoyed Cola drinks. What is more, more rural dwellers than urban dwellers drank coffee $(39.1 \%$ versus $23.5 \%$ ). This difference is significant at $\mathrm{p}=0.038$. With regard to harmful health practices, there is a correlation with this and level of formal education attained (primary education $-40.6 \%$, beyond high school $-40.9 \%$, vocational $-32 \%$ and normal high school $-17.4 \%$ ). This is particularly evident with respect to the consumption of alcohol, of those who listed themselves as having only a primary education, $90.6 \%$ consume alcohol, for those with normal high school, this figure is $87 \%$, for vocational school $-82 \%$, and for levels of education higher than the fore-going $-72.3 \%$.

Over half of the surveyed population think that recreation and holidays are for undertaking some sort of motor activity,

TABLE 1 Attained formal education and knowledge of healthy eating practices.

\begin{tabular}{|c|c|c|c|c|c|c|c|c|c|c|}
\hline \multirow{3}{*}{ Knowledge about healthy feeding } & \multicolumn{8}{|c|}{ Education } & \multirow{2}{*}{\multicolumn{2}{|c|}{ Total }} \\
\hline & \multicolumn{2}{|c|}{ Basic } & \multicolumn{2}{|c|}{ Vocational } & \multicolumn{2}{|c|}{ Normal High School } & \multicolumn{2}{|c|}{ Higher } & & \\
\hline & $\mathrm{N}$ & $\%$ & $\mathrm{~N}$ & $\%$ & $\mathrm{~N}$ & $\%$ & $\mathrm{~N}$ & $\%$ & $\mathrm{~N}$ & $\%$ \\
\hline Very high & 0 & $0 \%$ & 0 & $0 \%$ & 3 & $6.5 \%$ & 8 & $36.4 \%$ & 11 & $7.3 \%$ \\
\hline High & 1 & $3.1 \%$ & 6 & $12.0 \%$ & 9 & $19.6 \%$ & 8 & $36.4 \%$ & 24 & $16.0 \%$ \\
\hline Average & 16 & $50.0 \%$ & 28 & $56.0 \%$ & 28 & $60.9 \%$ & 6 & $27.3 \%$ & 78 & $52.0 \%$ \\
\hline Low & 15 & $46.9 \%$ & 16 & $32.0 \%$ & 6 & $13.0 \%$ & 0 & $.0 \%$ & 37 & $24.7 \%$ \\
\hline Total & 32 & $100.0 \%$ & 50 & $100.0 \%$ & 46 & $100.0 \%$ & 22 & $100.0 \%$ & 150 & $100.0 \%$ \\
\hline \multicolumn{11}{|c|}{ rho Spearman' $=0.524, \mathrm{p}=0.000 * *$} \\
\hline
\end{tabular}

TABLE 2 The planning of taking-up some sort of active motor activity, versus age.

\begin{tabular}{|c|c|c|c|c|c|c|c|c|c|c|}
\hline \multirow{3}{*}{$\begin{array}{l}\text { Are you planning to take up } \\
\text { some form of motor activity? }\end{array}$} & \multicolumn{8}{|c|}{ Age } & \multirow{2}{*}{\multicolumn{2}{|c|}{ Total }} \\
\hline & \multicolumn{2}{|c|}{$40-59$ years } & \multicolumn{2}{|c|}{$60-69$ years } & \multicolumn{2}{|c|}{$70-79$ years } & \multicolumn{2}{|c|}{80 years and more } & & \\
\hline & $\mathrm{N}$ & $\%$ & $\mathrm{~N}$ & $\%$ & $\mathrm{~N}$ & $\%$ & $\mathrm{~N}$ & $\%$ & $\mathrm{~N}$ & $\%$ \\
\hline Yes & 30 & $71.4 \%$ & 33 & $62.3 \%$ & 14 & $42.4 \%$ & 6 & $27.3 \%$ & 83 & $55.3 \%$ \\
\hline No & 12 & $28.6 \%$ & 20 & $37.7 \%$ & 19 & $57.6 \%$ & 16 & $72.7 \%$ & 67 & $44.7 \%$ \\
\hline Total & 42 & $100.0 \%$ & 53 & $100.0 \%$ & 33 & $100.0 \%$ & 22 & $100.0 \%$ & 150 & $100.0 \%$ \\
\hline
\end{tabular}


while one third think such are for recuperative purposes, and $11.3 \%$ think these are for passive practices. Just over half of the participants $(55.3 \%)$ plan to undertake more motor activity. The survey reveals that more women are active physically $(64.3 \%)$ than are men $(47.5 \%)$. The Spearman's test shows that this correlation is weakly significant $(\mathrm{P}=0.039)$. Of note, increased age correlates with decreased activity, the percentages being $71.4 \%$ for those from 40 to 59 years of age, and only $27.3 \%$ for those 80 years of age or greater (Table 2).

The relationship between age and the planning to takeup some form of motor activity is significant statistically, yet there is a quite weak correlation between the variables $(p=0.002)$. In terms of origin, more urban residents $(65.4 \%)$ plan to be more active than do rural residents (43.5\%). Amongst the respondents, the intended motor activities include walking, cycling, and cardio-vascular exercises. Statistically significant is that more women $(24.3 \%)$ than men $(7.5 \%)$ plan to take up nordic walking $(\mathrm{p}=0.004)$, and indeed, more women $(21.4 \%)$, than men $(8.8 \%)$ plan to take up swimming $(\mathrm{p}=0.029)$. Of significance is that $40 \%$ of all women and only $10 \%$ of men plan to take up cardio-vascular exercises. Correlation in this case is quite weak $(p=0.000)$. Age and the planning of taking up a cardiovascular fitness exercise regime is more highly significant $(p=0.006)$, the correlation being negative with increased age. Age influences also the intention to take up walking as an exercise $(\mathrm{p}=0.035)$, as does the intention to undertake cycling $(p=0.019)$ for cardio fitness purposes. The majority of those intending to take up walking are between the ages of 60 to 69 years $(54.7 \%)$, while those 80 and above are at $18.2 \%$. With regard to biking, the figure for those between 60 to 69 years of age is $39.6 \%$ of the total surveyed.

Regarding formal education levels achieved, the relationship between those of higher formal education of respondents and the intention to take up nordic walking is significant statistically ( $\mathrm{p}=0.001)$, as is the taking up of cardio-vascular exercises (highly significant at $\mathrm{p}=0.012$ ). Almost half of those surveyed $(45.3 \%)$ are planning to take up some sort of physical activity on account of their own health. Doing so is considered important by $3.3 \%$ of all respondents, but of less importance for 5.3\%. However, sustaining an acceptable level of physical fitness is very much an important reason for taking up some sort of physical activity for $14.7 \%$

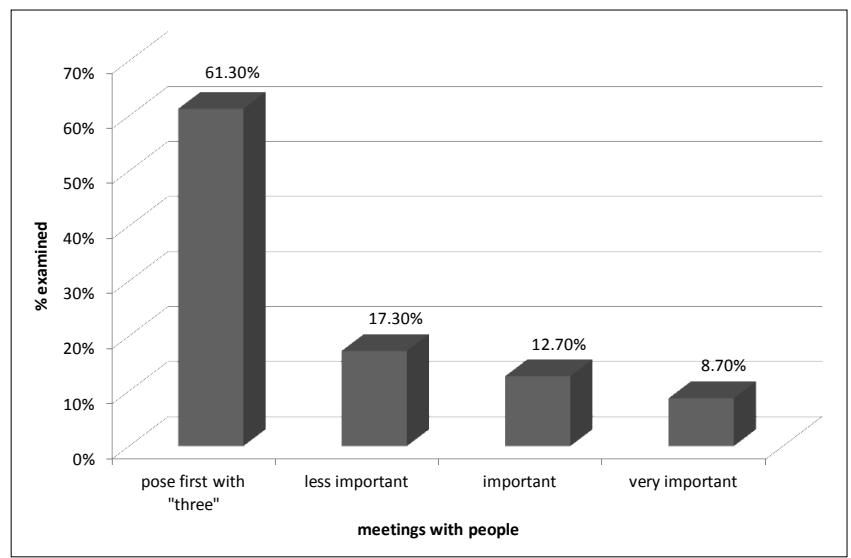

FIGURE 1. Caring about one's own health as a reason for taking-up some sort of physical activity. of all those surveyed, and an important reason for as many as $26.7 \%$ (Figure 1 ).

The respondents also assessed the influence of the physical activity on the prevention of individual diseases. The prevalent view is that increased physical activity has a positive effect on the prevention of obesity and type II diabetes (which is the reality), and a much lesser positive effect on alleviating backaches, and a far less effect on preventing osteoporosis. About changes of lifestyle following treatment, the source of preventative practices is most often nurses $(39.9 \%)$ or doctors $(39.9 \%)$. Of note, $13.5 \%$ of the entire study group stated that no-one gave out such information.

To sum up, the results of our survey indicate that caring about one's own health is an important reason for taking up some sort of physical activity, of lesser importance is sustaining present levels of physical fitness. However, it can be said, that among the surveyed such physical activity is more an obligation, rather than a source of pleasure.

\section{DISCUSSION}

Cardiovascular diseases are a major health problem in Poland, and they have profound influence on lifestyle. In our work, we determined whether patients knew and understand, why the disease they had, developed, as well as whether they understood the behaviours to modify to prevent recurrence or to minimize complications.

Over half of the respondents declared that they possessed average knowledge about healthy eating, however, the greater the age, the less knowledge is possessed. Yet, the correlation between variables is quite weak $(\mathrm{p}=0.001)$. Of dietetic recommendations, more women are in the know than are men, and those of very good financial circumstances are more aware than are those less so. What is more, a greater number of men follow unhealthy life-style choices than do women - for example, smoking $(90.7 \%)(p=0.149)$, and alcohol consumption $(84 \%)(p=0.986)$. These results are similar to those of R. Poręba, A. Derkacz, R. Andrzejak et al., who based their study on a group of students at the University of Wrocław. In their work, of 240 in their study group, only $17.4 \%$ followed healthy dietary practices [3].

Healthy eating practices are of primary importance in maintaining the health of Poland's population, and the current situation is not compatible with the recommended models [3]. We are consuming too few vegetables and fruits, or cereals and milk, as we prefer a diet built upon the consumption of meat. We are also omitting fish dishes in the diet. The result of these dietary choices is a deficiency of polyunsaturated fatty acids, omega-3, selenium, vitamin D and iodine [3]. We also practice sedentary lifestyles. Indeed, in our study group, only $55.3 \%$ of the total population are planning to undertake increased physical activity. In addition, more women than men plan to do so $(64.3 \%$ of the former, and $47.5 \%$ of the latter). and younger persons (71.4\%) have greater intentions to do so than do older persons. However, while the relationship between age and implementing any sort of motor activity is significant statistically, in our study group this exhibits a quite weak correlation between variables $(p=0.002)$. Similarly, our study saw that more urban residents are active $(65.4 \%)$ as against those who are 
residing in rural areas. Hence, here again, the relationship between residency and intention to undertake additional physical activity is weakly significant $(\mathrm{p}=0.007)$. Walking and cycling are the most frequent forms of intended or practiced physical activity. Of all intended or practiced physical activity, only $14.7 \%$ of all respondents chose swimming.

Our study also reveals that self-care is an important reason for the intention of increased physical activity, doing so for pleasure or because of medical recommendations are distant choices. These results are similar to those of Poręba, Derkacz, Andrzejaka et al. with regard to a population group composed of students. Here, a low degree of physical activity was demonstrated. Only one seventh of the study group undertook physical activities in their leisure time, and only one tenth did so daily [3]. Poręba, Derkacz, Andrzejaka et al. noted that the students preferred swimming (93.1\%), running $(28.6 \%)$, cycling $(27.0 \%)$ and fitness room activities (14.3\%) in a descending order [3]. Węgrów et al., in their study conducted amongst residents of Warsaw and Tarnobrzeg, noted that about $70 \%$ of all respondents factor in the state of their health in the life styles they follow [4]. Moreover, A. Ołtarzewska, J. Sawickiej-Powierza, D. Rogowskiej-Szadkowska, S.Chlabicz and L.Marcinowicz, in their work, also saw that the patients within their study showed great awareness of risk factors in the development of cardiovascular diseases. In a ranking of what should be lifestyle choices in preventing the onset of such diseases, they chose maintaining a healthy body weight and not smoking (93.3\%), control of cholesterol and glucose levels (91.7\%), and following a well-balanced diet (89.2\%) [4]. Moreover, $75 \%$ of all respondents also chose the following of some sort of fitness regime.

\section{CONCLUSIONS}

Patient knowledge of healthy eating and lifestyle practices after heart surgery is dependent upon age and level of formal education. The relationship is negative for increased age, but positive for increased level of formal education achieved. What is more, the following of dietetic recommendations after heart surgery will depend on the sex, financial circumstances and the marital status. In addition, more women follow such recommendations than do men, and those of very financial situation do so more than those of good or poor financial circumstances. Furthermore, the same situation is seen with widows and widowers, as opposed to those still married. However, a combination of formal education level achieved and place of residence has not a significant influence on health knowledge and the life style choices followed by men. Furthermore, sex, residency and level of formal education achieved have a positive correlation with intention to undertake healthful physical activities, with women and younger persons and those with higher formal education being more active.

\section{REFERENCES}

1. Łaciński M, Dytfeld D, Sarnowski W. Kardiochirurgia-historia i teraźniejszość. Poznań: Akademia Medyczna im. Karola Marcinkowskiego; 2002.

2. Kałka D, Sobieszczańska M, Pilecki W, Adamus J. Kompleksowa rehabilitacja kardiologiczna w strategii prewencji wtórnej choroby sercowonaczyniowej. PoL Merkuriusz Lek. 2009;XXVII(157):31.

3. Poręba R, Gać P, Zawadzki M, et al. Styl życia i czynniki ryzyka chorób układu krążenia wśród studentów uczelni Wrocławia. Pol Arch Med Wew. 2008;3:118.

4. Ołtarzewska AM, Sawicka-Powierza J, Rogowska-Szatkowska D, et al. Wiedza pacjentów ze środowiska wiejskiego na temat czynników ryzyka i profilaktyki chorób układu krążenia. Pol Merkuriusz Lek. 2010;XXVIII(165):203.

Corresponding author

Agnieszka Narloch

7/6 Bzowa Str., 80-376 Gdańsk

E-mail: cholok6@wp.pl 